\title{
TRANSORAL ENDOSCOPIC-ASSISTED EN BLOC RESECTION OF MUCOEPIDERMOID CARCINOMA: AN ALTERNATIVE TO EXTRA-ORAL ROUTE
}

\author{
Yasser Nabil * and Alaa Ghita **
}

\begin{abstract}
The most common approache for the resection of mucoepidermoid carcinoma of the maxilla are the extraoral conventional incision. The standard treatment is en bloc resection with wide safety margins and subsequent reconstruction of the jaw, the resulting scars could be devastating to the patient's postoperative appearance. In this study we reported endoscopically assisted approach that offers a less aesthetically invasive technique, with complete removal of the lesion. Four patients were included, they were diagnosed of having mucoepidermoid carcinoma by clinical examination, computed tomography imaging in saggittal and coronal planes, and preoperative fine-needle aspiration biopsy. They had endoscopically assisted resections through intranasal approach to resects the upper and the proximal medial extension of the lesion, while the rest had been removed through the trans-palatal route. A pre operative primary acrylic splint was prefabricated to act as a primary obturator. All the resections were successful without recurrence after 2 years follow up. Endoscopically assisted resection of such lesions provides it complete removal with excellent cosmetic results. With this technique there was no facial paralyses, nor recurrences, with excellent aesthetic and functional results. The patients returned back to normal in the short term. It provides a viable alternative to conventional approaches.
\end{abstract}

KEY WORDS: Endoscope, mucoepidermoid carcinoma.

\section{INTRODUCTION}

Salivary gland neoplasm accounts for approximately $5 \%$ of all head and neck tumors. Mucoepidermoid carcinoma is one of the most common malignant tumors of salivary tissue. When affecting intraoral minor salivary glands it can be considered in the differential diagnosis of oral reactive lesions. Mucoepidermoid carcinoma is a relatively common salivary tumor with varying potential for aggressive behavior. The diagnosis of Mucoepidermoid carcinoma is based on the findings of three intermixed elements: mucin-producing cells, intermediate clear cells, and squamoid cells ${ }^{(1)}$

\footnotetext{
* Lecturer and Consultant of Oral and Maxillofacial Surgery, Head of the Oral and Maxillofacial Department, Specialized Dental Teaching Hospital, Cairo, Egypt

** Consultant of Ent, Ear and Nose Department, Kobry Kobba Military Hospital, Cairo, Egypt
} 
Primary central mucoepidermoid carcinoma of the jaws accounts only for $2 \pm 3 \%$ of all mucoepidermoid carcinomas reported $^{(2,3)}$.

The current standard of care for treatment of malignant jaw tumors is en bloc resection with wide margins to prevent recurrence ${ }^{(4)}$ The majority of these tumors are low-to-intermediate grade which has no positive lymph node involvement, and treatment involves complete resection with negative margins ${ }^{(5,6)}$. The use of endoscope in oral and maxillofacial surgery has become increasingly common in recent years. A popular application is for temporomandibular joint arthroscopy and subcondylar fracture management. It was also used for removal of frontal osteomas, and condylar osteochondroma through an intraoral approach ${ }^{(7,8)}$. Our objective in this prospective clinical study was to assess the outcome of endoscopic-assisted en bloc resection of law grade mucoepidermoid carcinoma of the palate and maxillary sinuses.

\section{PATIENTS AND METHODS}

Four patients with swelling involving the palate and extended towards the maxillary sinuses. Were selected for this series, which was collected at the Department of Oral and maxillofacial surgery, of the specialized dental teaching Hospital, Cairo, Egypt. The group included 1 man and 3 women aged between 42 and 53 years. They all presented with a nodular well-defined swelling at the hard palate, measuring 2-4 cm Fig. (1). The lesions were progressed slowly. Aspiration was negative. Axial and coronal computed tomographic examination revealed a well defined expansible mass that extended to the maxillary sinus Fig (2). Radiographic examination and a presumptive radio-graphic diagnosis of mucoepidermoid or pleomorphic adenoma. Incisional biopsy was performed under local anesthesia and revealed a low-grade mucoepidermoid carcinoma, histopathological examination revealed neoplastic cells, with an epidermoid and mucoid substances, the cells showed hypercromatism, and nuclear pleomorphism. All patients were given detailed explanation of the procedure and gave full written consent.

\section{Instruments}

The endoscopic images were viewed and recorded using an endoscopic camera,(Karl Storz GmbH \& Co. KG, Tuttlingen, Germany). It is composed of a cool light source (175- W Xenon lamp), a fibre-optic cable and a rigid endoscope of $30^{\circ}$ endoscope with an outside diameter of $4 \mathrm{~mm}$.

\section{Surgical procedure:}

Endotracheal intubation was performed using Isoflurane Orion, Egypt. The endoscope was introduced trans-nasally. We dissected between the lesion and the sinus walls under endoscopic visualization. A bipolar coagulator was used for haemostasis. Sufficient illumination and magnified viewing allowed anatomical structures to be clearly identified and protected. The camera connected to the endoscope eyepiece captured the images fig.(3). Incision was then carried out inferiorly at the hard palate surrounding the lesion with safety margin of $5 \mathrm{~mm}$. Dissection was then carried out to detach all soft tissues at the caudal aspect of the lesions and up wards to meet the endoscopic dissection, and the tumor was then completely removed in one piece fig.(4). Intra-operative frozen sections showed that the tumour were completely resected. an acrylic obturator that had been fabricated before surgery, was introduced. The prosthesis recreates a partition between the oral and nasal cavities, restores facial contour, improves mastication, articulation, and speech. Final prosthesis was fabricated six months after surgery. All the resections were followed up clinically and radiographically for 2 years. 


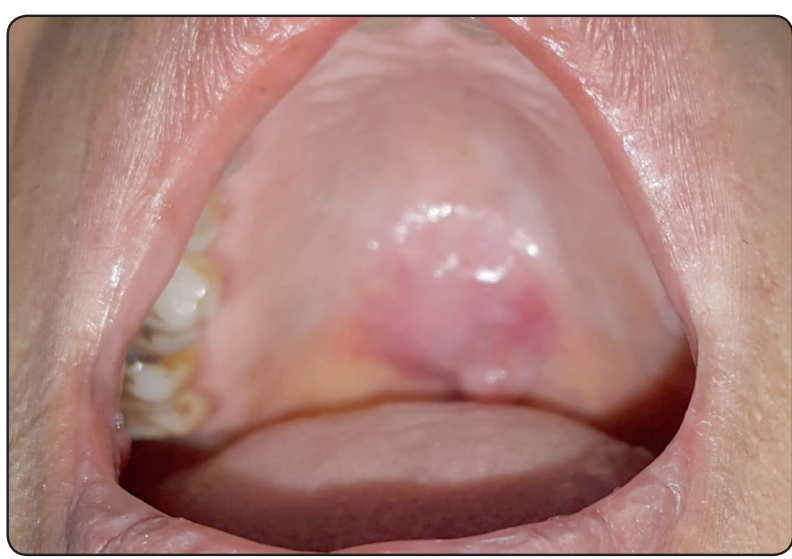

Fig. (1) Pre operative radiograph of a mucoepidermoid carcinoma of the palate.

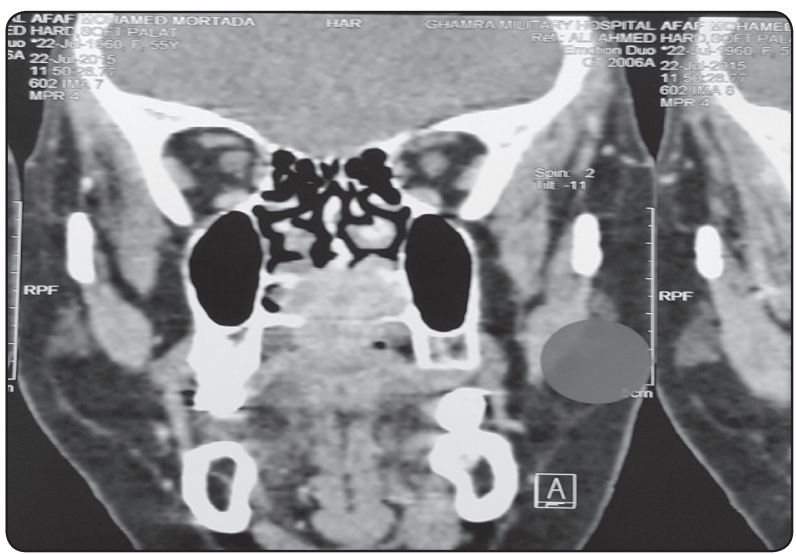

Fig. (3) Coronal computed tomography of the lesion.

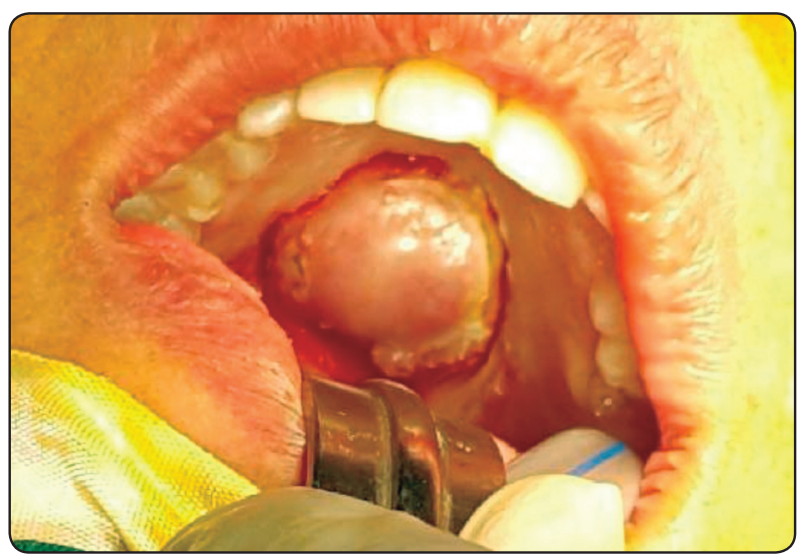

Fig. (5) Intra operative view of the caudal incision of the lesion trans- orally.

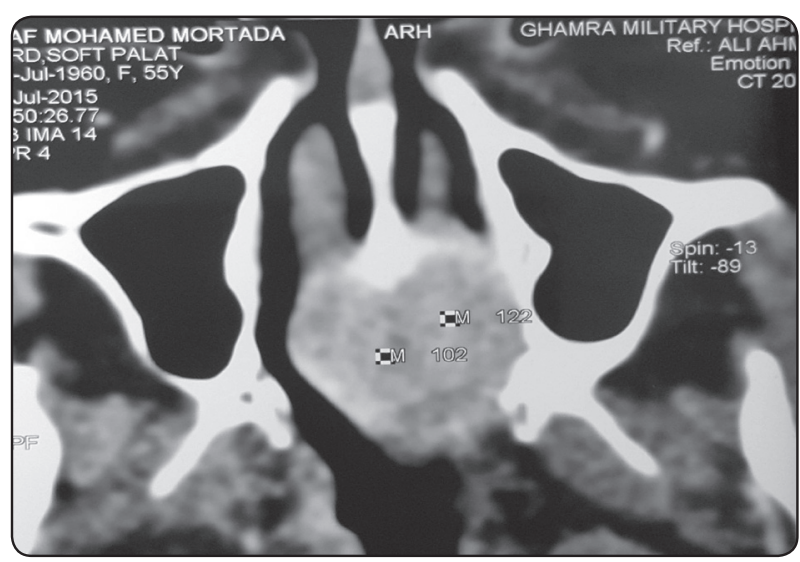

Fig. (2) Axial computed tomography of the lesion.

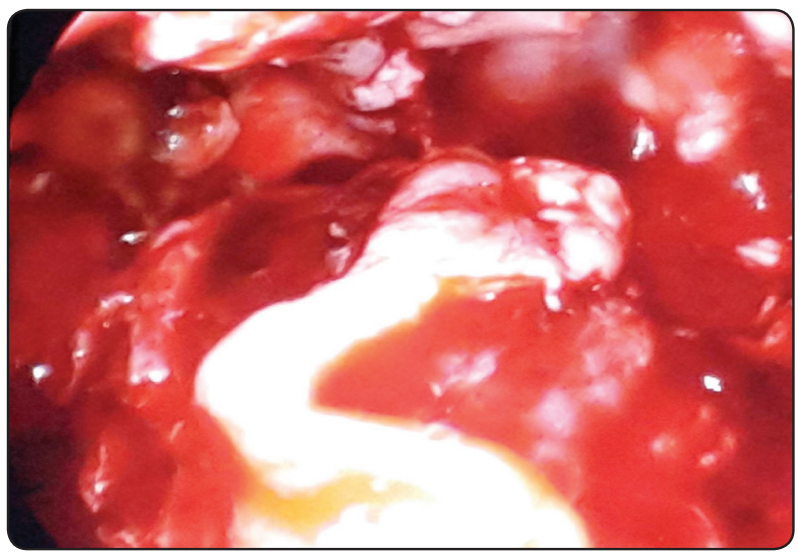

Fig. (4) Endoscopic view of a dissected upper end of the lesion.

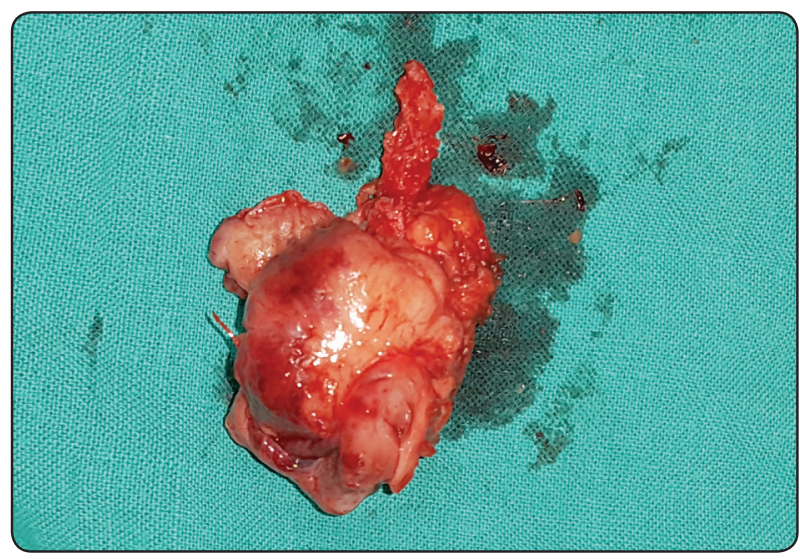

Fig. (6) Complete resection of the lesion. 


\section{RESULTS}

Using the modified endoscopic approach the surgeon, we did part of the procedure under the endoscope, this increased the complexity of the operation, with the addition of special equipments and hence coast. It consumes more time than conventional approach. (The average time of the operation was 3.5 hours). In addition to reduced surgical site morbidity and excellent cosmetic results without extra-oral scars, the endoscopic assisted approach offered faster recovery. All the resections were successful without recurrence after 2 years follow up.

\section{DISCUSSION}

Resection is the primary treatment for Mucoepidermoid carcinoma. Extra oral incisions have been described to allow easy access of the tumor, with the resulted disfiguring scars. Endoscopic assisted surgery became incorporated as a part of the oral and maxillofacial surgery over the last decade. It has been used in fixation of subcodylar fractures, excision of cheek lipomas, in brow and mid face lifts, and benign tumours and cysts of the frontal region.

Endoscopic resection is a minimally invasive technique which results in smaller scars, with good visualization and magnification of the surgical field, it could be an alternative method for those patients prone to keloid scarring. Endoscopic approach decreases potential neurovascular impairment and overall allows a faster patient recovery time ${ }^{(9,10)}$. It has been reported that there is a reduction in incidence of infection in patients undergoing endoscopic surgery ${ }^{(11)}$.

The current study conferms that endoscopically assisted resection of such lesions provides it complete removal with excellent cosmetic results. With this technique there was no facial paralyses, nor recurrences, with excellent aesthetic and functional results. The patients returned back to normal in the short term.
It provides a viable alternative to conventional approaches. With increasing usage the equipment costs and operative time will decrease.

\section{REFERENCES}

1- Kim S, Park M, ChoY, Myoung H, Lee J, Lee S Modified functional obturator for the consideration of facial growth in the mucoepidermoid carcinoma pediatric patient International Journal of Pediatric Otorhinolaryngology, Volume 79, Issue 10, October 2015, Pages 1761-1764

2- Gingell JC, Beckerman T, Levy BA, Snider LA. Central mucoe-pidermoid carcinoma. Review of the literature and report of a case associated with an apical periodontal cyst. Oral Surg 1984;57:436 \pm 9.

3- Ezsias A, Sugar AW, Milling MAP, Ashley KF. Central mucoe-pidermoid carcinoma in a child. J Oral Maxillofac Surg 1994;52:512 \pm 5 .

4- Martin J.W. , Chambers M.S., Lemon J.C., Toth B.B., Helfrick J.F.: Prosthodontic and surgical considerations for pediatric patients requiring maxillectomy, Pediatr. Dent. 17 (2) (1995) 116-121.

5- Triantafillidou K., Dimitrakopoulos J., Iordanidis F., Koufogiannis D.: Mucoepidermoid carcinoma of minor salivary glands: a clinical study of 16 cases and review of the literature, Oral Dis. 12 (4) (2006) 364-370.

6- Caccamese Jr J.F.., Ord R.A.: Paediatric mucoepidermoid carcinoma of the palate, Int. J. Oral Maxillofac. Surg. 31 (2) (2002) 136-139.

7- Foustanos A, Zavrides H. Endoscopic resection of forehead osteomas.Br J Oral Maxillofac Surg 2007;45:392-5.

8- Yu HB, Sun H, Li B, et al. Endoscope-assisted conservative condylectomy in the treatment of condylar osteochondromathrough an intraoral approach. Int J Oral Maxillofac Surg 2013;42:1582-6.

9- Foustanos A,1, Zavrides H: Endoscopic resection of forehead osteomas British Journal of Oral and Maxillofacial Surgery 45 (2007) 392-395

10- Li B, Zhang L, Zhao z, Shen G, Wang X: Minimally invasive endoscopic resection of benign tumours of the accessory parotid gland: an updated approach British Journal of Oral and Maxillofacial Surgery 51 (2013) 342-346

11- Bostwick J, Evans EF, Nahai F, editors. Endoscopic plastic surgery. St Louis: Quality Medical Publishing; 1995. p. 6. 